\title{
The Cultural Integration of Knowledge Management into Interactive Design
}

\author{
Javed Anjum Sheikh, Bob Fields, and Elke Duncker \\ Interaction Design Centre, \\ School of Engineering \& Information Sciences, \\ Middlesex University, London, UK \\ $\{j$.anjum, b.fields, e.duncker\}@mdx.ac.uk
}

\begin{abstract}
This research is being conducted to address the integration of cultural factors in interactive information system to enhance the reach of knowledge management to culturally heterogeneous user. In this context, we introduced a knowledge management framework. This method will help researchers to understand how different cultures view similar concepts. The result and analysis we expected in this research is intended to guideline to design knowledge management based cross-cultural interface. The result will increase usability enhancement and interaction patterns in interactive design.
\end{abstract}

Keywords: Cultural Integration, Cultural Interface, Cultural Representation, Cultural Design, Knowledge Management, Usability, User Interaction.

\section{Introduction}

This research focuses on cultural knowledge management and managing cross-cultural differences. The research describes emerging issue of cultural categorization with the context of Knowledge Management. The cultural and human context is often overlooked by Information System (IS) and Knowledge Management (KM) practitioners. The main problem is to capture cultural knowledge and its presentation. The purpose of this paper is to discuss cultural knowledge with respect to information technology. The truly effective cultural knowledge management is not only translating text but the development of a tool to represent similar cultural concepts for global user.

In what follows, we review related works on culture and design in section two. In section three we describe our research methods. Section four presents the results of our study and the analysis thereof. Following a discussion of links to interaction design in section five, our conclusions and directions for future work are presented in the last section.

\section{Background}

Cross-cultural issues exist in every aspect of our lives. When two peoples get together than culture clash starts. Normally people accommodate, sublimate or ignore culture 
difference due to common ground, shared goals same interest. The difficulties arise when people consider language, ethnic or racial background, religious beliefs, gender, age, education in depth. There are many avenues to take that will help cultures 'get along' better: identifying and concentrating on improved communication, fostering mutual respect, engendering co-operation and shared visions. Then, all kinds of cultures can work side by side to everyone's benefit. The concept of culture is most commonly associated with anthropology. Further disciplines using culture as a concept and thereby focusing on specific aspects of culture are sociology, psychology, economy, and computer science. Every person gets more satisfaction in their own cultural environment as it helps to increase efficiency and productivity. The studies by $[1][2][3][4][5][6]$ show that culture plays a vital role to understand the psychology of any nation. The main problems area is cultural factors and their acceptance and without considering these cultural factors, knowledge management cannot be useful for everyone. The research on cultural differences [7][8], is inadequate in its context, whereas research investigating user point of view in cultural differences [9][10] needs attention.

All of these studies attributed differences to various cultural styles: including searching style, cognitive style, language use, perceptions of search systems and information sharing. The most important cultural clash is lack of culturally specific classification system. Classification is the process in which objects are grouped and classified which are rooted in people's experience. Classification systems are way of organising knowledge. Currently used classification schemes are Dewey Decimal Classification (DDC), Library of Congress Classification (LC), Universal Decimal classification (UDC), Cutter's Expansive Classification, (CEC), Bliss's Bibliographic classification (BBC), and Ranganathan's Colon Classification (RCC). They claim to be universal schemes but these suffer from an inherent bias. They have great possibilities of expansion, alteration and adjustment only for new western subjects. However these schemes are failed to classify local material in appropriate ways. This means that classifications made by one culture can be difficult to access for another culture Fig 1.

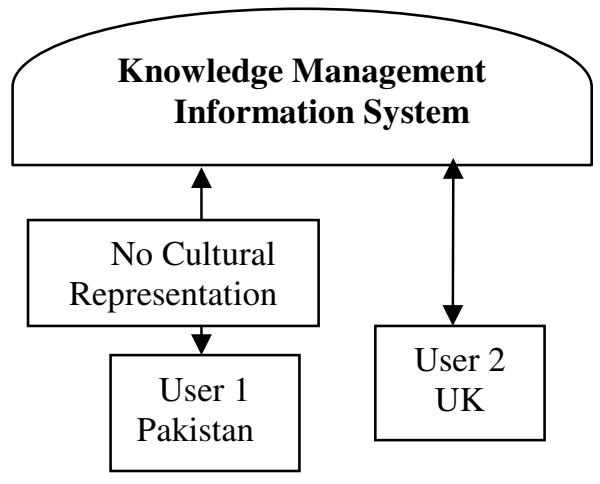

Fig. 1. The Problem 


\section{Methods}

Researchers use Hofsted's Model without keeping in mind that his model is not only too rigid [15] but also has very general views [1] about different cultures. It is also not appropriate for Cultural based knowledge management system [16] being a business model [2]. Therefore, Hofstade's concept of cultural dimensions (Individualism vs. Collectivism, large vs small Power Distance, strong vs. weak Uncertainty Avoidance and Masculinity vs.Femininity) has limited impact for this research.

Cultural specific study is an important phenomenon in research, but computer scientists neither consider it to be an essential element for them nor do they think the user is important, [17][18].The results of studies by [13][19][6] show computer scientists face difficulties in the successful integration of culture into computer application

The knowledge management researchers focus their study on organizational culture $[20][21][22][23]$.The researchers focus on explicit knowledge and failed to fully incorporate Nonaka and Takeuchi's model [24]. As we know there are two types of knowledge, namely tacit and explicit knowledge. Tacit knowledge resides in the mind of individual and is difficult to capture and document. Whereas Explicit knowledge can be captured and documented. We are using both types of knowledge to achieve successful cultural knowledge. The researchers focus on explicit knowledge and failed to fully incorporate Nonaka and Takeuchi's (2005) model. We are using Nonaka model to capture not only explicit but also tacit knowledge fig 2 .

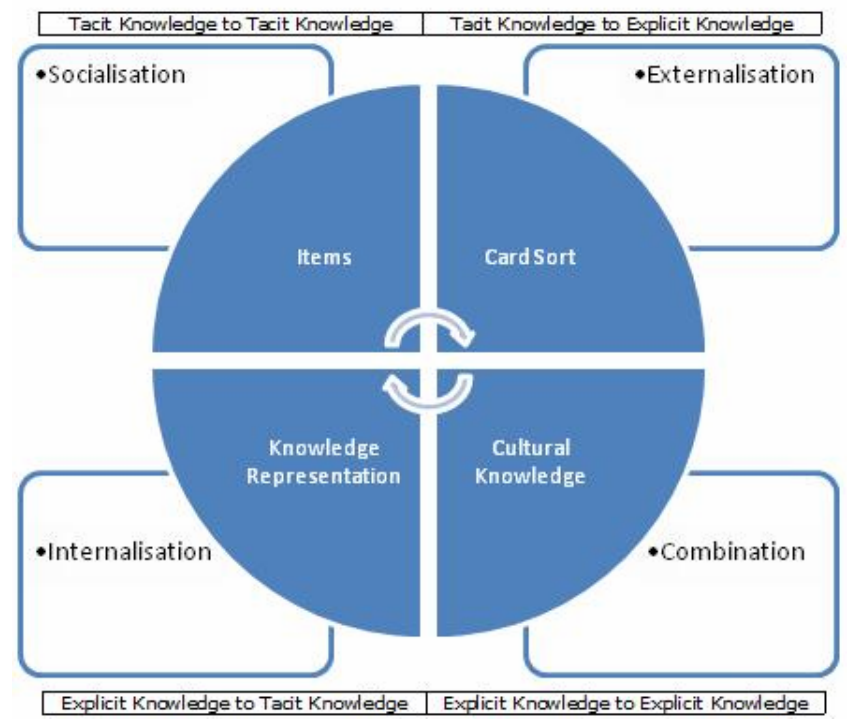

Fig. 2. Cultural Knowledge Management Model

The most important cultural clash is lack of culturally specific system. For instance, none of these systems are fully capable of classifying and organising material for cross-cultural user. In Western culture this problem is not very much acute but in 
non-Western culture, it is very confusing and perplexing resulted retrieval of information is not up to mark. Duncker, [25] emphasises on to create system for crosscultural user. Therefore it is need to integrate cultural differences with interaction capabilities [26].

\subsection{The Study}

In order to approach the question of how different cultures organise their knowledge differently, we employ a research approach based on card sorting. In a card sorting study participants are typically asked to arrange into groups, cards on which the names of objects are written. Such studies can reveal something about the ways that participants organise their knowledge of the world. The approach is widely used for initial exploration, in the field of knowledge acquisition [27]. It helps to develop and identify concepts, models, attitudes, trends, patterns and values for capturing information from the mental model of the participants. The mental model generates concepts and suggests possible taxonomies.

Card sorting is widely used in Human Computer Interaction, psychology, and knowledge engineering for knowledge elicitation. It helps to evoke participants' domain knowledge [13] distinguish the level of the problem [28] and reflects ideas about knowledge [29]. This research investigates the cultural classification by using the Card Sorting technique as an effective method to identify categories of food items. Card Sorting is often used to gather data about personal construct for instance menu structure specification and to understand users' perceptions of relationships among items. These experiments use one layer of grouped card. Our card sorting technique is different. In that we in ask subjects to further classify the groups of cards, if they wish to do so.

The following method is adopted to conduct the studies. Thirty-nine printed cards were used, each carrying the name of a distinct food item that participants would be asked to group together with other items. The purpose of this study was to examine and demonstrate the differences in the way participants from Pakistan and the UK categorise entities. We chose Pakistan and the UK for field study, as both countries are multi-cultural, multi faith and have sub-cultures.

The domain chosen for this research is food items as these are very common to everyone. As the study was conducted in Pakistan, the food items were translated into the Urdu language as closely as possible.

\subsection{Participants}

A group of 160 participants (80 PK and $80 \mathrm{UK}$ ) took part in this research. The participants recruiting process in Pakistan ran smoothly, but we encountered difficulties in recruiting UK participants, due to criteria (of pure British). Because of the recruitment method, it was not possible to achieve gender-balance especially in the UK. None of the participants recruited for the Pilot Study was used again in the main study. No post study interviews were conducted

All participants provided written informed consent. The study was reviewed and approved by the Middlesex University Ethics Committee. 
As the study was a cross-cultural one, the food items were translated into the participant's first language where appropriate. Participants were asked to classify items in several steps Figure 3. First they grouped items and gave labels to each group. Then they were asked to further divide the group if they wish to do so. The steps of grouping and labelling are repeated until the subject no longer wants to subdivide the groups of items. When subgroups were produced, the participant was asked to provide a name for that group. This usage is in contrast to many popular applications of card sorting, where participants are asked to organise the cards into groups, without further sub-categorisation to generate a deeper tree of classifications.

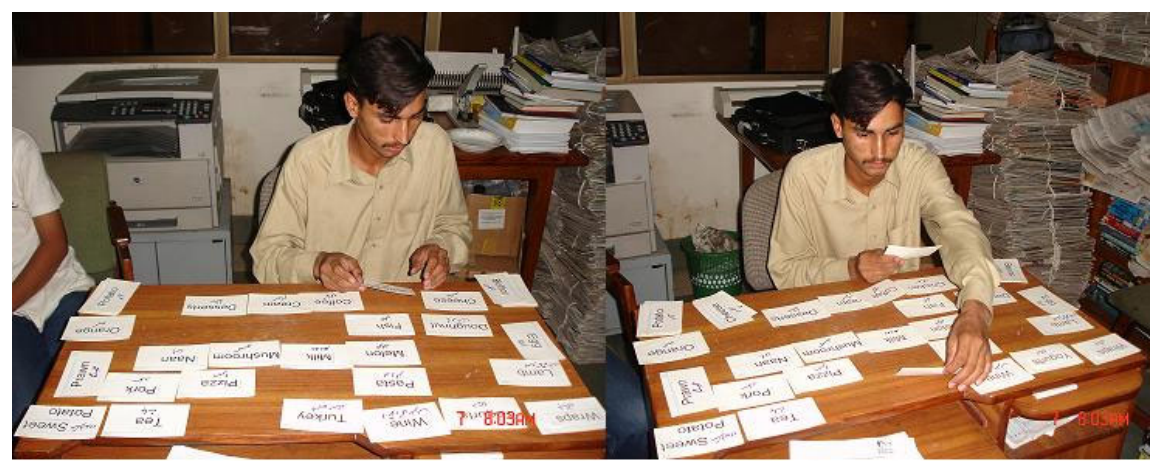

Fig. 3. Card Sorting experiment

\section{Findings}

\subsection{Observations}

This study shows a unique result compared to other studies. There is a large difference in categorization in the respect of culture, faith and environment. The following presents some examples from the studies to support this claim:

- Educated participants have western perception about prohibited items in Islam.

- Pakistani women are less privileged; they receive only religious education or basic education. Consequently, their perception of prohibited items is faith oriented.

- Participants faced difficulty to categorize items like Doughnut, Pasta, Pizza, as they are not familiar with these items.

- Few participants from Siraiki culture categorized items according to their profession

- It has been observed that this culture has a strong Islamic influence. The participants in this study have less western influence on their categorisation.

- Although some food items were categorized easily, some other items can be placed in two categories and some were unfamiliar to participants.

- Some items were ambiguous for participants and they tried to place them into two categories. 
- Some participants were not familiar with some items, and interpreted them differently.

- Some participants sorted items into groups and sub groups whereas others in a more general way.

The initial analysis of the study indicates a cultural difference in food categorisation among people belonging to different cultures that appears to be greater than the differences between people within the same culture. The studies suggest that both the 'national culture' and the 'belief system' of a participant shape the way they categorise items. By 'belief system' here, we refer roughly to religious background as this is a highly significant factor in the way people understand food and the various domestic practices that surround it. It seems likely that other elements of culture, such as professional cultures or membership of communities of practice would gain greater significance.

\section{Discussion}

Based on our findings, we can more confidently assert that categorisation is influenced by culture and belief, and several open questions exist as to the nature of this influence.

A first step towards conducting analysis in a more rigorous manner was to formalize the complimentary notions of 'similarity' and 'difference' that are at work. A number of possible formulations are possible, but the one that proved to be most promising was the notion of 'edit distance': the difference or distance between two tree structured hierarchies is considered to be the number of editing steps necessary to transform one tree into the other. This measurement of distance was implemented in software based on a freely available framework called SimPack. ${ }^{1}$

The algorithm for computing the 'edit distance' between trees facilitated the construction of a 'distance matrix' that encodes the edit distance between the hierarchies produced between all pairs of study subjects, and the discovery of structure in the population of subjects entails an exploration of this distance matrix.

Two approaches to this exploratory task were employed. A more traditional statistically-based approach was implemented using a variant of the k-means cluster analysis algorithm to discover clusters of subjects who were 'close together' in that they produced similar hierarchies. This formal style of analysis was complemented with a more exploratory tool that produces a visualization of the distance matrix, based around the physical analogy of data points joined by a collection of springs whose length is determined by the edit distances ${ }^{2}$. A simulation of such a system yields a dynamic network that tends to settle in a 'low energy' configuration. The latter technique provides a useful visual way of seeing how a structure emerges from the confusion, as similarly similar trees tend to gravitate towards one another.

\footnotetext{
${ }^{1} \mathrm{SimPack}$ is an open source collection of software tools for investigating the similarity between 'ontologies'. Available from http://www.ifi.uzh.ch/ddis/simpack.html

${ }^{2}$ The tool is based on the Graph demonstration program that is part of the Java Software Development Kit available fromjhttp://java.sun.com
} 
The results obtained from the cluster analysis algorithm are, informally, at least, in accord with the graphical simulation. Figure 5 illustrates this by showing the graphical display in which subjects are shown as numbered nodes in the graph. The physical distance between nodes in the figure is a reflection of the network of edit distance relationships. Overlaid on the figure are the four clusters found by a run of the cluster analysis algorithm.

A starting assumption for this research was that no scheme for organising information is likely to be equally effective for a range of cultural groups. The current research aims to make a contribution in this area, not by finding a universal way of classifying information, but by providing a method for investigating classification in a locale in order to generate localised interface designs. The expected solution will be based on local user access needs and capability of the local users.

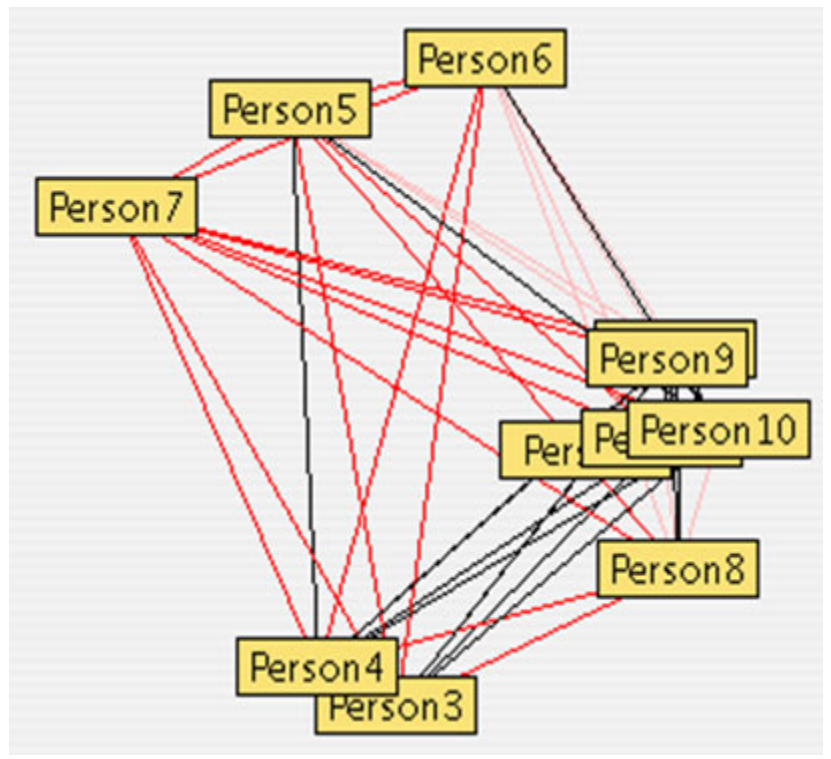

Fig. 4. Overlaying cluster analysis on a graphical representation

The analysis so far has given a way of identifying clusters of related structurings of a set of objects. A number of strategies exist to take this forward into interaction design. An obvious approach is to provide a localized user interface for each cluster, choosing a representative element from a cluster (for example, using the edit distance metric to find the most central element in a cluster) to guide the structure of navigation elements on an interface.

If they try to go beyond this point, they are automatically asked, whether they would like to order the pdf, and are given instructions as to how to do so.

Please note that, if your email address is given in your paper, it will also be included in the meta data of the online version. 


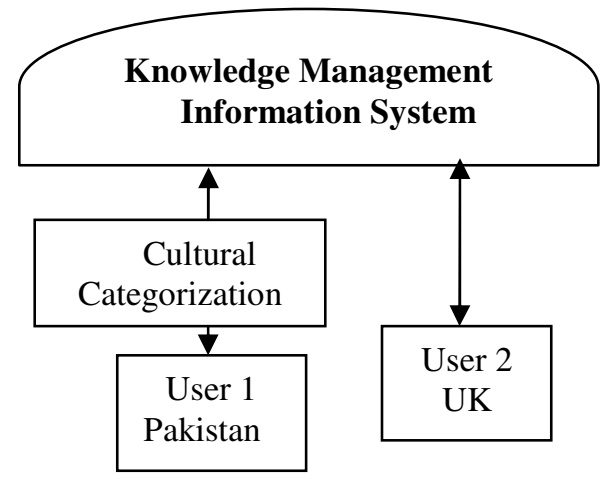

Fig. 5. The Solution

\section{Conclusion and Future Work}

The contribution of this research is to introduce a new analysis technique based on SimPack's modified classes to discover/measure similarity and edit distance. This method will help to understand how different cultures view similar concepts.

We propose a cultural based interface obtained from cultural knowledge. Our interface will show a common concept which is result of hierarchical clustering analysis of multi cultural representation. It will allow user to explore effectively in comparison to a non-cultural based interface.

The interface is user perspective, which will help the user to interact effectively and close to human to human interaction. When the users visit the main page the interface user will find cultural based navigations/classifications close to the particular culture. If the user clicks on a particular culture for example Pakistan, the user will get additional options from four cities. We hope this will enable the reader to understand the problem and its solution will give them better overview of this research. The aim of this research is to propose a design for all cultures to increase usability enhancement and interaction patterns in categorizing that lead to browser design. The result and analysis we presented in this paper is intended to guide design of crosscultural interface. We used mixed methods to interpret the result. Our studies explored cultural difference by card sorting and result analysis through cluster analysis to compare both cultures. Significant differences were found in term of categorisation. The result increase usability enhancement and interaction patterns in categorising that lead to interface design.

\section{References}

1. Bourges-Waldegg, P., Scrivener, S.: Representations, the central issue in cross-cultural interface design. Interacting with Computers 9(3), 287-309 (1998)

2. Del Galdo, E., Nielsen, J.: International User Interfaces. Wiley Publishing, New York (1996) 
3. Evers, V.: Human Computer Interfaces: Designing for Culture, Masters Thesis Faculty of Mathematics, Informatics, Physics and Astronomy, University of Amsterdam, Amsterdam (1997)

4. Minocha, S., French, T., Dawson, L.: Cultural Attractors of Usability and Customer Relationship Management in (B2C) E-Commerce Environments. In: Gunter, K., et al. (eds.) Culture and HCI: Bridging the Cultural and Digital Divides. Conference (6th: 2003). Proceedings of the 2nd British Computer Society Human Computer Interaction Workshop, pp. 37-47. University of Greenwich, London (2003)

5. Sun, H.: Building a culturally-competent corporate web site: An exploratory study ofcultural markers in multilingual web design. In: ACM Special Interest Group for Design of Communications. Conference (10th. 2001). Proceedings of the 19th Annual International Conference on Computer Documentation, pp. 95-102. ACM Press, New York (2001)

6. Yeo, W.: Global-software development lifecycle: An exploratory study. In: Proceedings of the SIGCHI Conference on Human Factors in Computing Systems, pp. 104-111. ACM Press, New York (2001)

7. Hofstede, G.: Culture's Consequences, 2nd edn. Sage, Beverly Hills (2001)

8. Masuda, T., Nisbett, R.E.: Attending holistically versus analytically: comparing the context sensitivity of Japanese and Americans. Journal of Personality and Social Psychology 81, 922-934 (2001)

9. Ein-Dor, P., Segev, E.: End-User Computing: A Cross-Cultural Survey. In: Proceedings of the Twenty-Third Annual Hawaii International Conference on Systems Science, vol. IV, pp. 240-250 (January 1990)

10. Igbaria, M., Zviran, M.: End-user effectiveness: a cross-cultural examination. Omega, Int. J. of Mgmt Sci. 19(5), 369-379 (1991)

11. Sheikh, J.A., Fields, B., Duncker, E.: Cultural Representation for Interactive Information system. In: Proceedings of the 2009 International Conference on the Current Trends in Information Technology, Dubai (2009)

12. Luong, T., Lok, J., Lok, S., Driscoll: Internationalization: Developing Software for Global Markets. Wiley, New York (1995)

13. Russo, P., Boor, S.: How fluent is your interface? Designing for international users. In: Conference Proceedings of the Conference on Human Factors in Computing Systems, pp. 342-347. Addison-Wesley Longman Publishing, Boston (1993)

14. Hofstede, G.: Cultures and Organizations. McGraw-Hill Book Company Europe, Berkshire (1991)

15. Nocera, J., Hall, P.: Making sense in intercultural software implementation. In: Gunter, K., et al. (eds.) Culture and HCI: Bridging the Cultural and Digital Divides. Conference (6th: 2003). Proceedings of the 2nd British Computer Society Human Computer Interaction Workshop, University of Greenwich, London (2003)

16. Sheikh, J.A., Fields, B., Duncker, E.: Cultural Representation for Multi-culture Interaction Design. In: Aykin, N. (ed.) Proceedings of the 3rd International Conference on Internationalization, Design and Global Development: Held As Part of HCI international 2009, San Diego, CA, pp. 99-107. Springer, Heidelberg (2009),

http: / / dx.doi.org/10.1007/978-3-642-02767-3_11

17. Fernandes, T.: Global interface design: A guide to designing international user interfaces. AP Professional, Boston (1995)

18. Sheridan, E.E.: Cross-cultural web site design: Considerations for developing and strategies for validating locale appropriate on-line content, MultiLingual Computing, Inc. (2001), http: / / www . multilingual. com (accessed 23/12/2003)

19. Hall, H.T.: Beyond Culture. Doubleday, New York (1976) 
20. De Long, D., Fahey, L.: Diagnosing Cultural Barriers to Knowledge Management. Academy of Management Executive 14(4), 113-127 (2000)

21. Jarvenpaa, S.L., Staples, D.S.: Exploring Perceptions of Organizational Ownership of Information and Expertise. Journal of Management Information Systems 18(1), 151-183 (2001)

22. Gold, A.H., Malhotra, A., Segars: A Knowledge Management: An Organizational Capabilities Perspective. Journal of Management Systems 18(1), 185-214 (2001)

23. Baltahazard, P.A., Cooke, R.A : Organizational culture and knowledge management success: Assessing the behavior-performance continuum (Working Paper). Arizona State University West (2003)

24. Nonaka, Takeuchi, H.: The Knowledge-Creating Company. Oxford University Press, New York (1995)

25. Duncker, E.: Cross-cultural usability of the library metaphor. In: Proceedings of the 2nd ACM/IEEE-CS Joint Conference on Digital Libraries, International Conference on Digital Libraries Archive (2002)

26. Khoja, S., Sheikh, J.A.: KIIT Digital Library: An open hypermedia Application. In: International Conference on Use of Information Technology in Teaching of Science, Islamabad, Pakistan, March 12-14 (2002)

27. Romaine, S.: Language in Society. Oxford University Press, Oxford (1994)

28. Barrett, A.R., Edwards, J.S.: Knowledge Elicitation and Knowledge Representation in a Large Domain with Multiple Experts. Expert Systems with Applications 8, 169-176 (1996)

29. Zakaria, J.S., Stanton, J.M., Sarkar-Barney, S.T.M.: Designing and implementing culturally sensitive IT applications. Journal of Information Technology and People 16, 49-76 (2003) 